\title{
Los oficios de la diversión en Roma
}

\author{
Entertainment professions in Ancient Rome
}

\author{
Javier Cabrero Piquero ${ }^{1}$ \\ FÉlix CoRdente VAQuero
}

\begin{abstract}
RESUMEN ABSTRACT
En este trabajo repasamos todos aquellos oficios que contribuyeron al disfrute del ocio entre los antiguos romanos. Los grandes espectáculos públicos: ludi circenses que agrupaban diferentes tipos de competiciones, siendo la más apreciada las carreras de carros; los munera, primero en el circo y luego en los anfiteatros, combates, cacerías y, ocasionalmente, batallas navales. Los ludi scaenici, representaciones teatrales de menor coste organizativo que los anteriores. A todo ello se añadieron las competiciones atléticas, la asistencia a las termas, la caza, etc.

In this paper, we are going to review all the professions that helped towards the enjoyment of the Ancient Romans. The great public shows: Iudi circenses, that got together different types of competitions like the Chariot racing, the most appreciated one; the munera, at first in the circus and later in the amphiteatres, fights, hunters and sometimes mock sea battles. The ludi scaenici, theatral plays, whose cost price was lower than the rest of the shows. In addition to all of this, we should add the athletic competitions, the termal baths, and the hunter and so on.
\end{abstract}

\section{PALABRAS CLAVE:}

Otium, munera, ludi circenses, ludi scaenici, certamina graeca, termas, caza, pesca.

\section{KEYWORDS:}

Otium, munera, ludi circenses, ludi scaenici, certamina graeca, termal baths, hunter, fishing.

La sociedad romana, sobre todo en las grandes ciudades, fue una sociedad enfocada en gran medida hacia la diversión. A decir de Juvenal ${ }^{2}$ y de Frontón ${ }^{3}$, el pueblo romano verdaderamente sólo tenía dos preocupaciones, comer y divertirse. Cuando hablamos de diversión entre los romanos, hubo tres tipos de espectáculos,

1 Departamento de Historia Antigua. Universidad Nacional de Educación a Distancia. jcabrero@geo.uned.es.

2 Juvenal, Sat., $\mathrm{X}, 78$

3 Fontón, Princ. Hist., 18, 22-24. 
que sin lugar a dudas, fueron los más populares y a los que más tiempo dedicaron: en primer lugar los Ludi Circensis, seguidos los Munera, y los Ludi Scaenicis.

Todos ellos dieron lugar a la aparición de un buen número de profesionales que hicieron posible su correcta puesta en funcionamiento.

Pero hubo otras diversiones, mucho más cercanas y menos fastuosas, que habría que encuadrarlas casi dentro del ámbito de lo privado, como las que se desarrollaban en los termopolia. Otras más cotidianas, como las ejercidas por los empleados de las termas o en los balnea y, finalmente, las había más ocultas como las que tenían lugar en las casas de lenocinio.

A todos ellos habría que añadir un innumerable grupo de artesanos, de cuyo trabajo salían infinitud de pequeños o grandes objetos, sin los cuales el ocio y la diversión en Roma, en muchas de sus vertientes, no habría sido posible.

Vamos a intentar aquí hacer un breve bosquejo de los principales oficios que hicieron que los romanos disfrutaran de una vida un poco más agradable.

Una vida que para algunos autores como Amiano Marcelino ${ }^{4}$, historiador del siglo IV, era demasiado disoluta, pues, según él, los ciudadanos romanos, no hacían nada serio ni constructivo y pasaban la vida dedicados al vino, a jugar a los dados y a divertirse en los espectáculos públicos, y de los 77 días que ocupaban a finales de la República, habían pasado a 177 en el siglo IV, es decir, un día de cada dos.

De ellos 101 se dedicaban a espectáculos teatrales, 66 a los circences y 10 a los munera o luchas de gladiadores. Este progresivo aumento no fue del gusto de todos los emperadores, y algunos como Nerva, Septimio Severo o Macrino, se opusieron a su crecimiento, pero sobre todo Marco Aurelio, quien intentó contener este crecimiento decretando que, al menos, 230 días al año serían dedicados al debate de las causas y a las discusiones de controversia jurídica ${ }^{5}$.

Sin lugar a dudas, la principal diversión de masas en Roma fueron las carreras que se desarrollaban en el circo. La afición de los romanos por las carreras arranca ya desde la monarquía y el primer lugar elegido para este tipo de espectáculo fue una llanura existente entre el Palatino y el Aventino, conocido como el valle Murcia que, por su especial configuración topográfica, permitió levantar el más importante edificio lúdico de Roma, el Circo Máximo, con una capacidad inicial de unos 150.000 espectadores ${ }^{6}$. César decidió aumentar su capacidad emprendió importantes trabajos de reforma, que fueron concluidos por Augusto, con una cabida cercana a los 250.000 asistentes $^{7}$. Posteriormente, Domiciano y sobre todo Traja-

${ }^{4}$ Amiano Marcelino, Hist. XXVIII, 4, 29: hi omne, quod vivunt, vino et tesseris inpendunt et lustris et voluptatibus et spectaculis: eisque templum et habitaculum et contio et cupitorum spes omnis Circus est maximus: et videre licet per fora et compita et plateas et conventicula circulos multos collectos in se controversis iurgiis ferri, aliis aliud, ut fit, defendentibus.

5 His. Aug. M. Aur. 10

6 Dionisio de Halicarnaso, II,62,3

7 Plinio, N.H., 36,24,102 
no, hicieron de él un referente para todos los circos del Imperio, llegando a tener una capacidad cercana a los 300.000 concurrentes.

Los ludi circenses, no estaban exentos de un cierto carácter religioso ${ }^{8}$, que quedaba patente en el desfile triunfal protagonizado por los principales dioses romanos y también algunos griegos, que se realizaba al inicio de los juegos. En este desfile participaban carros lujosamente adornados, tirados por cuadrigas y sólo una vez concluido podían dar comienzo los espectáculos. Tertuliano ${ }^{9}$ hace una crítica descripción de una parte del desfile: «porque en el fondo siempre tienen una base idólatra que les da vida y consistencia y les convierte en culpables. Los juegos circenses, sin embargo, parece que tengan un aparato más pomposo que espléndido. A ellos precede un magnífico cortejo, llamado pompa o procesión y en ella queda palpable el carácter que tienen, con todos aquellos simulacros e imágenes. Hay carros, además de coches, literas, todo tipo de asientos y a continuación, coronas, reliquias».

En este cortejo ritual o pompa nos encontramos ya con los primeros oficios imprescindibles para el espectáculo. Se trata de los músicos, los primeros de ellos, los trompeteros, que junto con los lictores precedían al magistrado encargado de presidir los juegos. Este magistrado unas veces iba a pie y, otras, subido en una biga, acompañado de un servus publicus, que sujetaba sobre su cabeza una corona de hojas de roble, a la manera de los generales victoriosos durante la ceremonia del triunfo.

El circo podía albergar espectáculos muy variados, que son mencionados por Cicerón ${ }^{10}$ y entre ellos habla de pugilato, de lucha, de carreras de carros y de caballos. El principal de ellos eran las carreras de cuadrigas, con especial atención a las que tenían lugar en las consualia ${ }^{11}$, fiesta, en honor de Conso, con el tiempo identificado con Neptuno ${ }^{12}$, que se celebraba el 20 de agosto y que estaba entroncada con los orígenes de Roma, concretamente con el episodio del rapto de las sabinas $^{13}$. En una primera época eran los propios dueños los que se encargaban de conducir los carros, pero cuando la participación activa en espectáculos públicos comenzó a considerarse poco digna para un ciudadano romano, la conducción de los carros se convirtió en un oficio, desempeñado por los aurigas que, mayoritariamente, eran libertos o esclavos, algunos de cuyos nombres han llegado hasta nosotros, como los conocidos Paulus y Marcianus, de un Mosaico del Museo Nacional de Arte Romano de Mérida. Más conocido y famoso fue Aurelio Polinice que logró un total de 739 victorias, o Aurelio Mollicio Tatiano con 125 victorias, ambos del siglo I. Ya en el siglo II Flavio Scorpo logró 2048 victorias y Pompeyo Muscloso 3559 .

\footnotetext{
8 Aulo Gelio, 3,10; Cicerón, Verr. 4,33.

${ }^{9}$ De Spectaculis 7,23.

10 De Leg. 2,38.

11 Varrón, I.I. VI,20; Paulo Festo, 38L.

12 Dionisio de Halicarnaso, I,32,2.

13 Livio, 1,9,6, Tertuliano, De Spectaculis, 5,5-7.
} 
Muchos de ellos pasaron a formar parte de una elite profesional, conocida por todos, que llegaban a ganar grandes sumas de dinero ${ }^{14}$. Por ejemplo, Aurelio Polinice sabemos que en tres ocasiones cobró un premio de 40.000 sestercios y en otras 26 uno de $30.000^{15}$. Entre los aurigas de origen hispano conocemos a Apuleyo Diocles, que logró la victoria en 1462 carreras y cuando se retiró a los 42 años, había ganado casi 34 millones de sestercios ${ }^{16}$.

Las carreras de cuadrigas en Roma, como ya hemos dicho, despertaban un entusiasmo febril, reflejado en la aparición de las llamadas factiones, primero dos y luego cuatro, agrupadas bajo cuatro colores: russata, albata, veneta, parasina (rojo, blanco, azul y verde). Con Domiciano se crearon dos nuevas: oro y púrpura, que apenas despertaron interés y desaparecieron muy pronto ${ }^{17}$. Incluso, en el siglo II, los colores rojo y blanco, que habían aparecido a finales de la República, aunque sin desaparecer del todo, fueron asimilados al verde y al azul. Tertuliano ${ }^{18}$ da una explicación al origen de estos colores: «Al principio sólo había dos colores, el blanco y el rojo: el blanco estaba dedicado al invierno, por el recuerdo del candor de la nieve; el rojo al verano, porque recordaba el fulgor del sol; la cosa con el tiempo tomo otro desarrollo, la superstición llevó a que algunos dijeran que el rojo era el color de Marte, el blanco lo consagraron a los Céfiros; a la Madre Tierra dedicaron un color entre verde y amarillo y por tanto a la primavera; al cielo, al mar y al otoño dieron el azul».

Cada uno de los colores podían aglutinar, familias y a decenas de miles de entusiastas aficionados. Algunos de ellos, fanáticos hasta el suicidio, como uno que en el 74 se arrojó a la pira funeraria de un auriga de la facción roja; los aficionados blancos decían que éste debía haber sido embrutecido por los efluvios de las esencias quemadas durante el funeral y en consecuencia no se habría arrojado a las llamas por propia voluntad ${ }^{19}$.

Todo era lícito para ayudar al equipo, incluso recurrir a la magia para que tus colores salieran vencedores y en algunas tumbas han aparecido tablillas de plomo con invocaciones a los demonios del lugar, para que hiciesen caer a un caballo o a un auriga.

Pero el entusiasmo y la pasión, al igual que en nuestro moderno fútbol, lo despertaban los colores, no los aurigas, los caballos o los carros. Un auriga podía correr para uno u otro color, dependiendo quien le contratara, y podía ser un héroe admirado si vencía para tu factio, o un villano odioso si vencía para la contraria.

14 Juvenal, Sat. VII,113-114.

${ }_{15}$ CIL VI, 10049a.

${ }^{16} \mathrm{CIL} \mathrm{VI,} \mathrm{10048,} \mathrm{incripción} \mathrm{en} \mathrm{la} \mathrm{que} \mathrm{aparecen} \mathrm{otros} \mathrm{aurigas} \mathrm{como} \mathrm{Publio} \mathrm{Emilio} \mathrm{Gutta} \mathrm{con} 309$ victorias para los azules y 824 para los verdes; o Cescente con 47 victorias y mas de un millón y medio de sestercios ganados.

17 Dion Casio LXVII,4; Suetonio, Dom. 7.

${ }_{18}$ De Spectaculis, 9,5: Namque initio duo soli fuerunt, albus et russeus. albus hiemi ob nives candidas, russeus aestati ob solis ruborem voti erant. sed postea tam voluptate quam superstitione provecta russeum alii Marti, alii album Zephyris consecraverunt, prasinum vero Terrae matri vel verno, venetum Caelo et Mari vel autumno.

19 Plinio VII, 186. 
De las 739 victorias de Aurelio Polinice, sabemos que 655 fueron defendiendo la factio roja, a 25 la verde, 12 a la azul y 17 a la blanca, y el hispano Diocles, venció 1361 veces para la factio roja, siendo el resto, hasta 1462 con alguna de las otras.

Las factiones del circo acabaron convirtiéndose en societates, autenticas empresas comerciales, dueñas o administradoras de cuadras de caballos, que tenían numerosos empleados, cuya misión era que las yeguadas estuvieran en las mejores condiciones posibles, se ocupaban de la doma, la limpieza, la reproducción cuando era necesario. Cuidaban sus heridas cuando se producción y, en definitiva, los tenían siempre a punto para que rindieran al máximo en las carreras.

Pero junto a ellos, había otro numeroso grupo de empleados, sin cuyo concurso el mundo de las carreras no hubiera sido posible. Hablamos, entre otros, de los constructores de carros. Imprescindibles para el espectáculo, eran expertos carpinteros y herreros, capaces de construir máquinas ligeras, pero resistentes y flexibles a la vez, que entorpecieran lo menos posible el galope de los caballos y que en las curvas fueran lo más estable posibles junto a ellos, los artesanos del cuero, zapateros y guarnicioneros, se encargaban de fabricar los atalajes necesarios. De confeccionar la vestimenta de los aurigas se encargaban sastres. Para los casos en los que ocurría algún accidente, algo frecuente en las carreras, se necesitaba el concurso de médicos y veterinarios, que curaran las heridas de hombres y de caballos. En un segundo nivel estaban mensajeros, expertos en propaganda y encargados de hacer proselitismo a favor de cada una de las factiones. No podemos olvidar otro tipo de empleados, como eran los maestros en conducción, generalmente antiguos aurigas que ya eran demasiado mayores y se encargaban de enseñar los secretos de la conducción a los noveles que empezaban en la profesión. También tenían un papel destacado los criadores de caballos, de los que las fuentes y la arqueología nos proporcionan numerosos testimonios. Sabemos que algunos de los más importantes eran hispanos, y que los caballos criados en Hispania eran famosos y muy apreciados en Roma ${ }^{20}$.

Sin embargo, los más apreciados eran los africanos. Conocemos los nombres de los caballos y su procedencia, utilizados por alguno de los aurigas famosos, así, Publio Elio Guta Calpurniano, defendiendo los colores azules alcanzó 92 victorias con el caballo Germinator, 105 con Silvano, 52 con Nitidius y 60 con Saxo, todos ellos africanos. Calpurniano también corrió para la facción verde, con los caballos Danao, Oceano, Victor y Vindice ${ }^{21}$. El primero sabemos que era africano y del resto desconocemos su procedencia.

Otro tipo de profesionales, sin lugar a dudas ligados a los bajos fondos de la ciudad, eran los corredores de apuestas. Los romanos sentian una pasión arrebatadora por el juego y las carreras era una actividad propicia y lucrativa para el que apostaba por los colores vencedores. Pero no sólo apostaban aquellos que

20 Plinio, N.H., XXXVII, 203; Simmaco, Ep. IV,58,2.

21 CIL VI, 10047 
iban a las carreras, la pasión era tal, que también lo hacían muchos que no asistían y estaban ávidos de saber los resultados. Sabemos que un vecino de Volterra, de nombre Cecina, ideó un sistema para comunicar a sus conciudadanos los resultados de las carreras utilizando golondrinas, que pintaba de los colores vencedores y dejaba volar a casa.

También eran muy habituales las apuestas entre particulares, la mayoría de las ocasiones amigos que las cruzaban a las puertas del circo, antes de que se iniciasen las carreras.

Esta costumbre de las apuestas es criticada, entre otros, por Tertuliano, quien señala que el pueblo acude como loco al espectáculo convertido en un tumulto atraído por las apuestas 22 .

Al margen de las necesidades de profesionales que requería el circo, los días de carrera sus alrededores se convertían en un autentico hervidero. Las calles que daban acceso a él y todo su entorno, se llenaba de todo tipo de profesionales que intentaban ganar dinero con las carreras, vendiendo todo tipo de productos como podían ser souvenirs, reproducciones de aurigas famosos representados en lucernas, prendas del color de su facción preferida, brocales de caballo, etc. también los adivinos ${ }^{23}$ ponían allí su consulta, vendiendo en secreto, a los crédulos, la información de quien iba a ser el vencedor. También se vendían alimentos de todo tipo ${ }^{24}$.

No podían faltar, al igual que en otros lugares donde se reunían grandes masas de población, prostitutas ${ }^{25}$ de todas clases, que ofrecían sus servicios a todo el que los pagaba.

Aún siendo las carreras la actividad más importante de las desarrolladas en el circo, durante años, hasta que hicieron su aparición otros edificios dedicados específicamente a ellas, acogieron una gran cantidad de espectáculos.

Hasta que se comenzaron a construir los estadios, el circo era también el escenario de luchas, pugilato y carreras pedestres. Se realizaban exhibiciones de acrobacias a caballo por los llamados desultores, que saltaban de un caballo a otro $^{26}$. Otro espectáculo eran los Ludi Troiani, una especie de simulacro de batalla entre jóvenes de la aristocracia ${ }^{27}$.

Hasta la aparición de los anfiteatros, en el circo también se realizaban las luchas de gladiadores y las cacerías o venationes.

En el año 80, Tito inauguró el Anfiteatro Flavio, y algunos de los espectáculos que hasta ese momento se habían desarrollado en el circo, pasaron a realizarse en

${ }^{22}$ Tertuliano, De Spectaculis, 16: Aspice populum ad id spectaculum iam cum furore venientem, iam tumultuosum, iam caecum, iam de sponsionibus concitatum.

23 Juvenal, VI, 582 ss; Ciceron, Div, I,132.

24 CIL VI, 9822.

25 Hist. Aug., Elag., 23,6 y 32,9 $18,39$.

26 Dioniso de Halicarnaso, 7,73; Cicerón, Mur., 27; Higinio, fab., 80; Livio, 23,29,5; Isidoro, Orig., 27 Suetonio, Aug., 43. 
su interior, pero este no fue el primer anfiteatro de Roma, ya en época de Augusto, Cayo Statilio Tauro había levantado un edificio parecido en el Campo de Marte, que sería destruido por el incendio de época de Nerón; y antes, en el año 53 a.C., Cayo Curio Escriboniano celebró unos juegos fúnebres en honor de su padre, hizo construir dos teatros uno junto al otro, eran de madera y estaban levantados sobre unos mecanismos que les permitían girar sobre un eje, de manera que las caveas podían quedar bien de espaldas, para que la representaciones respectivas pudieran hacerse sin molestar una a la otra, o bien una frente a otra, resultando así un anfiteatro, para acoger otro tipo de espectáculos, como en este caso los juegos fúnebres ${ }^{28}$.

Al igual que en el circo, en el anfiteatro se desataban las pasiones, como quedó demostrado en los sucesos acaecidos en Pompeya en el año 59, durante unos juegos organizados por Livineyo Régulo. Los habitantes de Pompeya y de Nocera, comenzaron a insultarse, y acabaron en una batalla campal en la que perecieron o fueron heridos un buen número ${ }^{29}$.

El senado decidió investigar lo sucedido, concluyendo que los responsables habían sido los pompeyanos a quienes se prohibió participar por diez años en espectáculos públicos y tanto Livineyo como los provocadores del incidente fueron condenados al exilio.

Antes de continuar con los oficios propios de este tipo de espectáculos, debemos preguntarnos por el significado de los munera gladiatoria.

Muy probablemente fueron introducidos por los etruscos en Roma. Durante siglos, los combates de gladiadores formaron parte de los rituales religiosos relacionados con el culto a los difuntos, al igual que en Etruria y el Grecia, aunque solamente tenemos noticias de ellos a partir de mediados del siglo III a.C., cuando en el año 264 a.C. D. Junio Bruto organizó un combate para honrar la memoria de su padre $^{30}$.

Esta tradición fue continuada por Emilio Lépido en el 216 a. C., por Escipión el Africano en el 206 a. C., en Cartagena, en honor de su padre y de su tío muertos unos años antes en Hispania; por Valerio Levino en el 200 a. C., etc.

La financiación siempre era privada, y solamente a partir del año 105 a.C., debido a la popularidad que habían adquirido, hasta el punto que hubo ocasiones en las que los asistentes a las representaciones teatrales abandonaron sus asientos a mitad de la función para asistir a lucha que iba a celebrarse ${ }^{31}$, el Estado decidió costear una representación anual.

El hecho de que los munera gladiatoria formaran parte del ritual religioso funerario, es muy probable que concediera a los que intervenían en ellos un indudable

\footnotetext{
28 Plinio, N.H., XXXVI, 116-117.

29 Tacito, Ann., XIV, 17

30 Livio, Epit. 16; Valerio Máximo, 2,4,7; Ausonio, Idyll. 11,36.

31 Terencio, Hec., prologus, 39-41.
} 
prestigio, recordemos que en un principio no eran privativos de los esclavos, sino que en ellos también intervenían ciudadanos libres por propia voluntad y, en muchas ocasiones, soldados, legionarios o auxiliares, que podían haber servido bajo las órdenes del difunto, demostrándole de este modo su agradecimiento y su respeto.

Para los esclavos, que con el paso del tiempo se convirtieron en los interpretes mayoritarios de estos «espectáculos», debía ser un motivo de satisfacción, además de un camino para comprar su libertad, el poder formar parte de estos rituales religiosos, pues sin duda les proporcionaba un cierto prestigio social, que dado su condición servil, sin duda les compensaba del riesgo que corrían.

Con la cada vez mayor popularización de los juegos, éstos, poco a poco se secularizaron, aunque todavía en época de César se dieron espectáculos gladiatorios de carácter fúnebre ${ }^{32}$, como los organizados por el propio César, durante su edilidad, en memoria de su padre, y que no pudo llevar a cabo con todo el esplendor que él hubiera deseado, pues el Senado limito a 320 el número de parejas que podían intervenir, temiendo que pudiera producirse una nueva rebelión semejante a la de Espartaco.

Esta secularización no debió ser muy del agrado de los gladiadores, que tuvieron que asistir a como su oficio dejaba de ser algo que era contemplado con admiración y casi reverencia, para convertirse en un simple espectáculo, en el que se jugaban la vida para entretener a unos ciudadanos ociosos, que no sentían ningún respeto por lo que ellos estaban haciendo y a los que lo único que les interesaba era el aspecto sangriento del combate.

Los gladiadores podían tener cinco orígenes diferentes:

1. Hombres libres condenados a muerte que salían a la arena sin armas (noxi ad gladium ludi damnati).

2. Hombres libres condenados a trabajos forzados (ad gladium). Una vez superado el combate obtenían la libertad.

3. Esclavos destinados directamente a este tipo de espectáculos.

4. Hombres libres que se sometían voluntariamente.

5. Esclavos alquilados por los propietarios para que actuaran en los munera.

El entrenamiento de los gladiadores se realizaba en un ludus, que era regentado por un lanista, que era el dueño. El adiestramiento propio era confiado a los doctores, expertos en el combate, que a menudo eran ayudados por veteranos que estaban jerarquizados, recibían el nombre de primus palus, secundus palus, o rudiarii. Cuando un gladiador llegaba al final de su carrera y había sobrevivido, como signo de su emancipación recibía la rudis, una espada de madera que simbolizaba su libertad.

${ }^{32}$ Cesar, B.C., 3,16,3; Salustio, Cat., 49,3; Plinio, N.H., 33,53; Suetonio, Ilul., 9.2; 10; Plutarco, Caes., 6.1-3. 
Monumentos e inscripciones nos hablan de diferentes tipos o clases de gladiadores:

Reciario: iba armado con una red en la mano derecha, un tridente y un puñal. Se protegía con el galerus o protector en brazo izquierdo. Su táctica de combate era mantener alejado al adversario para capturarlo con la red.

Secutor: también llamado contraretiarius, pues era su adversario habitual. Iba armado con una espada corta y se protegía con un casco liso, escudo grande rectangular y protecciones en le brazo y pierna derechos.

Mirmilo: Armado con espada, iba protegido con un casco adornado con un pez, escudo de grandes dimensiones y protecciones en el brazo derecho (manica) y pierna izquierda (greba). Su adversario solía ser el reciario, pero también el tracio, el oplomaco y el provocator.

Traex: o tracio, iba armado con una espada habitualmente curvada (sica) y se defendía con un casco rematado con un grifo, escudo pequeño (o parmula), grebas altas y manica en la derecha.

Hoplomaco: armado con lanza y puñal, se defendia con un casco de visera adornado con plumas, grebas altas, manica y escudo.

Provocator: Armado con espada, protegía su cabeza con un casco, el pecho con un escudo adornado con la efigie de la gorgona, escudo rectangular grande, grebas y protector del brazo derecho.

Eques: o caballero, iba armado con una espada larga, necesaria para combatir desde el caballo y se defendía con casco, escudo redondo y protección para las piernas.

Pero había otras muchos como el Paegniarius, que utilizaba como arma un baston curbo por uno de sus extremos (pedum) y vestía túnica y casco abierto; el sagittario que utilizaba arco y flechas; el Dimachareus, que iba armado con dos cuchillos; o el esedario que combatía sobre un carro (esseda).

La arena fue tan popular, que incluso se dio que algunas mujeres decidieron bajar a ella para combatir. Algo que fue rechazado por muchos autores. Así dice Juvernal33: «¿Qué pudor puede mostrar una mujer que lleve el yelmo y haya renunciado a su sexo?».

En el anfiteatro no solo se desarrollaban las luchas de gladiadores, también acogían otro tipo de espectáculos como las venationes o cacerías, que, como hemos dicho, con anterioridad se desarrollaban en el circo. Se trataba de la lucha de hombres contra fieras, que por primera vez tuvo lugar en el 186 a.C., el organizador de este espectáculo fue Fulvio Nobilior, que según Livio ${ }^{34}$ había ofrecido como voto en la guerra etólica, y que como novedad incluyó una cacería de leones y

з3 Juvenal, Sat., VI, 252.

${ }^{34}$ Livio, XXXIX, 22,1-3 
panteras, cacería que debió ser impresionante, pues señala que era comparable a las de su época. Con el paso del tiempo fueron aumentando el número de animales, panteras, osos, elefantes, hipopótamos, cocodrilos y todo tipo de animales que eran muertos por bestiarii o venatores.

Una de las mayores cacerías tuvo lugar en época de Trabajo, para celebrar su victoria sobre los Dacios. En esta ocasión combatieron diez mil gladiadores y salieron a la arena 10.000 bestias feroces $^{35}$.

En algunas ocasiones el espectáculo consistía no en la caza, sino en ver la lucha entre dos animales y ver cual de los dos salía victorioso; un ejemplo de esto era la lucha de búfalos contra elefantes, leones contra tigres. Podía suceder que la lucha fuera entre dos animales atados entre si, y cuando uno de ellos perecía, el otro recibía la muerte de manos de un venator ${ }^{36}$.

Para poder realizar estos espectáculos existían cazadores expertos, que eran los encargados de capturar a los animales y transportarlos a Roma, bien ellos personalmente, o bien todo tipo de intermediarios.

Finalmente, el anfiteatro era el lugar donde también se realizaban las naumaquías o combates navales. Para ello, el foso donde estaba la arena era llenado de agua. Sobre el agua se colocaban barcos representando dos naciones diferentes y en ellos iban prisioneros condenados a muerte, llamados naumacharii cuya misión era combatir por el país que representaban ${ }^{37}$. Habitualmente las escenificaciones de batallas navales, que habían tenido lugar en épocas anteriores, habían sido dentro del ámbito privado, en pequeños estanques. El primero en elevar la categoría de estos espectáculo fue Cesar $^{38}$ en el año 46, a.C., quien en el Campo de Marte creó un lago artificial en el que se enfrentaron las flotas tiria y egipcia formadas por birremes, trirremes y cuadrirremes. La organización de este tipo de festejos era extremadamente caro, pues además del agua que debía rellenar el foso, era necesario construir los barcos, a ello se sumaban las dificultades técnicas, por lo que las naumaquías raramente tenían lugar.

La tercera de las grandes pasiones de los romanos, en lo que a la diversión se refiere, era el teatro, que sin duda era el tipo de espectáculo más habitual y menos costoso. Hasta época muy avanzada no tuvo un edifico estable que acogiera las representaciones ${ }^{39}$, pasando de asistir en pie en las primeras épocas a los teatros estables como en de Pompeyo ya a mediados del siglo I a.C. ${ }^{40}$.

Los Iudi scaenici estaban muy ligados a las fiestas religiosas y podían tener carácter fijo o extraordinario. Entre las fijas destacan: los Ludi Palatini en Enero; los Ludi Megalenses, los Ludi Ceriales y los Ludi Floreales en Abril; los Ludi Apollina-

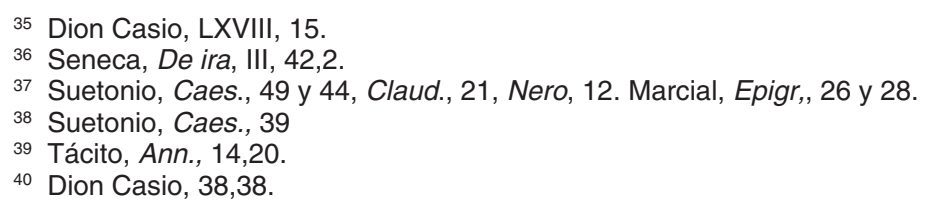


res en Julio; los Ludi Romani en Septiembre y los Ludi Plebei en Noviembre. A estas representaciones que se llevaban a cabo todos los años se añadían otras de carácter extraordinario que estaban originadas por diversos motivos como la consagración de alguna obra pública (Ludi Dedicatorii); como consecuencia de alguna promesa (Ludi votivi); motivados por una victoria militar (Ludi Triumphales), etc.

La mayoría de los tipos de obras que se van a representan en los teatros romanos van a tener un origen griego y los primeros autores se inspirarán en composiciones helénicas para escribir sus obras. Sabemos que la primera representación teatral llevada a cabo en Roma, en el verdadero sentido de la palabra, se llevará a cabo en el 240 a. de C. y fue organizada por los ediles con motivo de los Ludi Romani, representándose en ella una comedia y una tragedia del griego Andrónico, pero fue cinco años más tarde, en el 235 a.C., cuando se representó por primera ves una obra de autor latino, concretamente de Nevio ${ }^{41}$. En las sesiones de teatro se interpretarán varias obras, lo que hacía que estas fueran extremadamente largas. En un principio se llevaban a cabo por la tarde, después de comer, y duraban hasta la hora de la cena. Con el paso del tiempo estas comenzaran por la mañana y duraran todo el día; los espectadores se llevaban la comida al teatro y para los que no lo hacían había reparto de golosinas y todo tipo de alimentos ${ }^{42}$.

La base principal de las representaciones teatrales la constituían las tragedias y las comedias. Hay que señalar que los romanos no tenían mucho interés en las representaciones trágicas ${ }^{43}$, que consideraban aburridas y sus gustos se encaminaban, sobre todo, a la comedia.

Los argumentos de estas últimas son muy variados, pero es característico que sean respetuosas en cierta medida con el poder establecido no siendo muy corriente las que ridiculizan a los personajes importantes de la vida pública de la ciudad.

Entre las obras de carácter trágico va a destacar la praetexta, genero creado por Nevio en el siglo III a. de C. Es un drama histórico que toma sus argumentos de las gestas romanas pero que no alcanzaría mucho éxito. A estas obras principales acompañan toda una serie de pequeñas representaciones que están destinadas a entretener a los espectadores durante los intermedios. Entre ellas podemos destacar: los flíaques ${ }^{44}$, conocidos por textos y vasos pintados. Estaban relacionados con el culto dionisiaco y tomaban sus argumentos de la vida ordinaria.

La atelana, que será la antecesora de la comedia romana y florece en época de Sila. Se caracteriza por abundar en temas obscenos y ridiculizar las clases sociales, y toma sus argumentos de la vida rústica. Era interpretada por cuatro personajes fi-

\footnotetext{
41 Aulo Gelio, Noct. Att., XVII,21, 44-45.

42 Stacio, Silv., 1, 6, 27-34.

43 Plauto, Amph., 51-52

44 Ateneo, 14,15
} 
jos, Dossenus ${ }^{45}$ que es el listo que todo lo sabe y siempre esta repartiendo golpes a los demás, Buccus personaje de un hambre insaciable que se pasa toda la representación comiendo, Pappus personaje anciano y de carácter bonachón y Maccus tonto del que todos se ríen y lleva todos los golpes.

Con el paso del tiempo la atelana será sustituida por el mimo. En él desaparecen los personajes fijos. Eran pequeñas piezas costumbristas que representaban escenas familiares con acciones banales y personajes soeces, siendo muy comunes los triángulos amorosos formados por la esposa y su amante y el marido ${ }^{46}$.

Si la atelana se inspiraba en la vida rústica, el mimo lo hacía, principalmente, en la vida urbana. En algunas ocasiones estas representaciones podían representarse en calles o plazas, en escenarios improvisados o incluso en la casa de particulares ${ }^{47}$.

Entre las obras dedicadas a los intermedios está también el embolium, pequeñas interpretaciones integradas por cantos, danzas y fragmentos musicales ${ }^{48}$, y las pírricas, danzas militares que tienen su origen en los ejercicios militares que realizaban los jóvenes espartanos ${ }^{49}$; algunas veces podían tener carácter báquico y en estas ocasiones también intervenían en ellas mujeres.

Por último existía un tipo de representación enteramente latino, la pantomima, en ellas se aunaban tres artes, el canto, la música y el mimo, en ellas se escenificaban temas mitológicos e historias de amor. Un actor iba cantando la obra en tanto que otro la iba interpretando mímicamente ${ }^{50}$. En algunas ocasiones el actor cantante era sustituido por un coro de voces ${ }^{51}$.

Los actores, para la representación, usaban toda una serie de instrumentos, y entre ellos van a brillar con luz propia las máscaras, fabricadas en multitud de materiales, destacando la madera y el barro, indudablemente fabricadas por artesanos especialistas que eran perfectos conocedores de su simbología. Eran arquetipos, de manera que los espectadores, al ver la máscara que llevaba el actor, ya sabían el personaje que iba a interpretar; a parte de esta utilidad, tenían otra más práctica si cabe, y era que por su particular disposición ayudaban a cambiar la voz haciéndola más potente y la boca de ellas actuaba a modo de bocina facilitando que el sonido llegase claro y diáfano a los espectadores más alejados.

No en todas las obras se utilizaron el mismo tipo de máscaras, sino que estas variaron con las diferentes obras y eran específicas para la tragedia, la sátira o la comedia $^{52}$.

45 Varrón, I.I., 7, 95.

46 Isidoro, Orig., 18,49

47 Plutarco, Sila, 36.

48 Ciceron, Pro Sest., 116.

49 Plinio, N.H.,7, 56, 204. Suetonio, Caes., 39,1.

50 Juvenal, 6,3.

51 Livio, 7, 2,8-11; Valerio Máximo, 2, 4,4.

52 Julio Pólux, Onomastikon, IV, 133-154, recopila los diferentes tipos de máscaras empleadas en el teatro. 
Los actores en Roma estaban muy mal considerados socialmente. Era una profesión ejercida principalmente por esclavos, libertos o extranjeros, y para las clases altas de la sociedad, senadores y caballeros, suponía un desprestigio social tener cualquier tipo de contacto con ellos ${ }^{53}$.

No era socialmente aceptable que un ciudadano recibiera visita o visitara él a actores, e incluso se comprometía si era visto hablando con uno de ellos en la calle ${ }^{54}$.

Esto está perfectamente constatado hasta la época de Diocleciano, pues hasta ese momento todos aquellos que habían subido a una escena para actuar estaban privados automáticamente de su honor. Fue él quien estableció algunas excepciones para aquellos que lo hubiesen hecho antes de la mayoría de edad.

Hasta tal punto llegaba el desprestigio social de los actores, que por ley les estaba prohibido el acceso a los cargos honoríficos municipales y coloniales e incluso sus descendientes no podían contraer matrimonio válido con los descendientes de senadores por línea masculina hasta el grado de biznieto o biznieta ${ }^{55}$.

Los senadores estaban obligados a expulsar a su mujer de casa si se demostraba que esta había participado en algún tipo de representación escénica, incluso las mujeres que participaban en las representaciones eran asimiladas legalmente a las prostitutas ${ }^{56}$.

A pesar de ello hubo algunos cómicos, casos excepcionales, que si que alcanzaron cierto prestigio social, como fueron el maestro de declamación de Cicerón, el Lanuviano Q. Roscio, que fue amigo personal del dictador L.C. Sila y Esopo, que legaría a sus hijos una importante fortuna ${ }^{57}$.

Pero fue en los ambientes palaciegos, ya en época imperial, donde alcanzaron su más alto prestigio, y no hubo emperador que no tuviera predilección por algún histrion o pantomimo, hasta el punto de convertirse en compañeros inseparables como en el caso de Nerón y Paris ${ }^{58}$.

En los días de representación el ambiente en las calles era muy semejante al de cuando había carreras en el circo o munera. La gente bulliciosa se agolpaba en la cercanía de los teatros. Había una multitud de personas que ofrecían sus servicios o vendían todo tipo de cosas y de vituallas. Los que habitaban en las proximidades tenían que soportar estoicamente el ruido de la calle, los malos olores provocados por la suciedad acumulada y la incomodidad producto del exceso de población.

El ocasiones, en los grandes días de espectáculo, la aglomeración y el deseo de llegar a los edificios de representación era tal, que se producían avalanchas de

\footnotetext{
53 Suetonio, Tib., 35.

54 Tácito, Ann., 1,77.

55 Digesto, 23,2,44.

56 Digesto, 23,2,47

57 Macrobio, Saturn., 2,10.

58 Suetonio, Domit., 3,1.
} 
personas que llegaron a ser muy peligrosas, hasta el punto de que en alguna de ellas se llegaron a producir víctimas mortales. Suetonio nos trasmite la noticia de dos senadores muertos por asfixia a consecuencia de una de estas avalanchas ${ }^{59}$.

Existía otro tipo de entreteniendo mucho menos popular, pero que también tenía su espacio dentro de la vida de los romanos. Se trata de los llamados certamina graeca, o carreras atléticas ${ }^{60}$. Sila celebró la 175 Olimpiada en Roma ${ }^{61}$ y César ordenó la construcción de un estadio de madera para la celebración de carreras durante tres días ${ }^{62}$. Sin embargo, este tipo de espectáculo no logró calar demasiado en los romanos y Augusto, que sí era favorable, decidió no incluirle en las manifestaciones lúdicas estables de Roma y los trasladó a Nicópolis, dándole el nombre de Actia, y debían celebrarse cada cuatro años ${ }^{63}$. Calígula, Claudio y Nerón intentaron introducir de nuevo las competiciones atléticas en Roma ${ }^{64}$ sin ningún éxito. Sólo a partir de Domiciano, con la institución del Agone Capitolino, el público romano comenzó a apreciar este tipo de espectáculos ${ }^{65}$, que fueron acogidos en un estadio construido en el Campo de Marte, el Stadium Domitiani, cuyos restos se pueden observar bajo la actual Plaza Navona de Roma.

Eran varias las disciplinas. La más apreciada era el quinquertium ${ }^{66}$, compuesto por salto de longitud, lanzamiento de jabalina, lanzamiento de disco, carrera de un estadio y lucha. Otro tipo de competición era la lampadedromia, una carrera de relevos por equipos, en la que una antorcha hacía las veces de testigo y con el tiempo, los atletas también llevaban un escudo redondo. Finalmente otro tipo de carrera era la que se realizaba con el equipo militar puesto, armadura y armas.

Entre las competiciones atléticas habría que incluir en esta época la realización de combates, concretamente lucha, en la que se utilizaban las piernas para atrapar al adversario, pugilato y pancracio en el que todo estaba permitido.

Los atletas estaban dirigidos por un xystarca. En ocasiones los atletas se agrupaban en asociaciones que eran dueñas de su propia palestra. Eran bien considerados y recibían numerosos privilegios de los emperadores. Con el tiempo el más apreciado fue la concesión de la ciudadanía romana.

En las proximidades de los grandes lugares de diversión, ya hemos dicho que había un colectivo que antes y ahora ocupaban un papel destacado en las preferencias de muchos de los que asistían a los espectáculos, se trata de la prostitución.

En Roma habría que distinguir entre las prostitutas callejeras (prostibula) y las meretrices. Las prostitutas callejeras estaban peor consideradas socialmente y

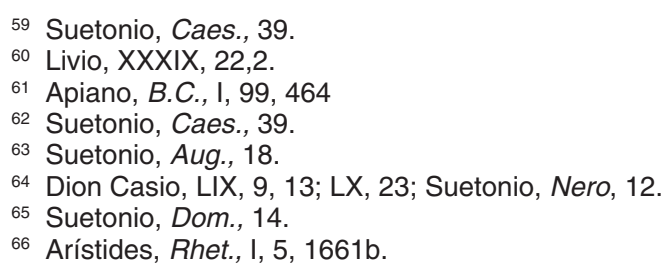


ejercían su profesión de día y de noche, mientras que las meretrices, mejor consideradas, sólo lo hacían de noche. Sin embargo, en Roma no parece que existieran prostíbulos tutelados oficialmente por el Estado.

Las casas de prostitución no podían abrir hasta pasada la hora nona (entre la 1:30 y las 2:30, dependiendo de la época del año) para que así no distrajeran de sus ocupaciones matutinas a los jóvenes. Las chicas que trabajaban en estas casas, dirigidas por un leno o una lena, podían ser esclavas o no. Cuando eran esclavas vivían permanentemente en la casa y todo lo que cobraban iba a manos del leno. Cuando se trataba de mujeres libres, generalmente tenían alquilada una habitación en la casa y tan sólo entregaban al leno un porcentaje de sus ganancias.

Una profesión que tuvo tantos siglos para desarrollarse no pudo evitar caer en la especialización y las prostitutas romanas se hicieron acreedoras de numerosos apelativos, dependiendo del lugar donde trabajaban (Lupae, lobas; Rufae, debido al color rojo de sus cabellos; Meretrices, merecedoras; Ambulatrices, paseadoras; Fornicatrices, por trabajar bajo los puentes o las arcadas de los edificios públicos; Noctilucae, por trabajar de noche; Bustuariae, por trabajar en las proximidades de las tumbas, etc). Eran fácilmente identificables, pues su vestimenta no era la que las matronas romanas utilizaban tradicionalmente. Acostumbraban a vestirse con la toga masculina, para así poder dejar al descubierto sus rodillas; además se teñían el pelo de rojo o se ponían una peluca de ese color, para así hacer pública cuál era su profesión. En la actualidad las luces rojas de determinados locales tienen el mismo significado.

Por su condición, las prostitutas se veían obligadas a no mantener ningún contacto con las demás mujeres. Podían participar de la vida religiosa, pero apartadas del resto. En el aspecto judicial también había diferencias, mientras que las matronas eran juzgadas en su propia casa por unos magistrados especiales, las prostitutas podían ser citadas en los tribunales públicos, incluso, a partir de cierta época, llegaron a pagar impuestos. Suetonio dice que Calígula fue el primero en obligarles a pagar una tasa equivalente al precio de un servicio ${ }^{67}$.

Por las inscripciones parietales de Pompeya tenemos una cierta noción de los precios usuales que las prostitutas de la ciudad solían cobrar. Las más bajas no iban más allá de los dos ases, un precio que era considerado insignificante. Las más jóvenes y hermosas podían llegar hasta los ocho o los nueve ases y algunas, como una cierta Attica llegaban a exigir 16, una cifra elevadísima si tenemos en cuenta que en esa época el salario de un legionario era 10 ases. Incluso alguna llegó a cobrar un denario, como puede leerse en un grafito pompeyano que dice: «por un denario, Arpócrates aquí folló a Arauca, con plena satisfacción».

Hasta aquí hemos bosquejado los oficios de las grandes diversiones. Sería discutible si para un romano, la asistencia a las termas era una diversión o una necesidad. Pero es una realidad que a ellas acudían casi a diario, eran lugar de en-

67 Suetonio, Gai, 40. 
cuentro y de esparcimiento. Coincidían con los amigos, comentaban los sucesos del día, hacían chistes, jugaban, cerraban negocios e, incluso, tramaban conspiraciones. En las termas ejercían su oficio un innumerable grupo de sirvientes que estaban a disposición de las personas que acudían a ellas, desde los encargados de mantener el fuego encendido para calentar los ambientes que lo requerían y el agua del caldarium, hasta masajistas que hacías más agradable la estancia.

Caza y pesca también estaban incluidas entre las diversiones privadas. Tanto una como otra requerían una indumentaria especial, túnicas cortas y protección en los hombros ${ }^{68} \mathrm{y}$, en campo abierto, necesitaban la ayuda de diferentes profesionales: vestigatores, o encargados de seguir las huellas ${ }^{69}$; indagador, que sacaba de su escondite a las fieras; alatores, grupos que a grandes gritos las espantaban; pressores o perseguidores de los animales en huida. Las herramientas para la caza eran hachas, arpones, jabalinas, lanzas, cuchillos, venablos, etc., todos ellos fabricados por artesanos armeros. Para la caza de aves o aucupium, el auceps ${ }^{70} \mathrm{o}$ cazador, empleaba lazos, hondas, redes, liga. Finalmente sabemos que los romanos también usaron de la cetrería para la caza ${ }^{71}$, aunque este arte debió ser muy rudimentario.

\section{BIBLIOGRAFÍA}

AA.VV.: Lo sport nel Mondo Antico. Ludi, munera, certamina a Roma. Roma, 1987. AA.VV.: Máximo, Espartaco y otras estrellas del espectáculo, Madrid, 2001.

AUDOLLENT, A.: Deflexionum tabellae, Paris, 1904.

AUGUET, R.: Cruauté et civilisation: Les jeux Romains, París, 1970.

BALIL, A.: La ley gladatoria de Itálica, Madrid, 1981.

BEARE, W.: I romani a teatro, Bari, 1986.

BIEBER, M.: The history of the Geek and Roman Theater, Princeton, 1939.

BILINSKI, B.: L'agonistica sportive nella Grecia antica. Aspetti sociali e ispirazioni letterarie, Roma 1961.

BLAZQUEZ, J.M.: «Criadores Hispanos de caballos de carreras en el Bajo Imperio en las Cartas de Simmaco", en Espacio Tiempo y Forma, Serie II Historia Antigua, 23, 2010, pp. 411-448.

BLAZQUEZ, J.M.: «Venationes y juegos de toros en la Antigüedad», en Zephyrus, 13, 1962, pp. 47-65.

CAMERON, A.: Circus facciones: Blues and Greens at Rome and Byzantium, Oxford, 1976.

CARCOPINO, J.: La vita quotidiana à Roma, Bari, 1978.

CAVALLARO, M.A.: Spese e spettacoli. Aspetti economico-strutturali degli spettacoli nella Roma giulio-claudia, Bonn, 1984.

COLINI, A.M.: Stadium Domitiani, Roma, 1943.

COLINI, A.M. y COZA, L.: Ludus Magnus, Roma, 1962.

COZO, G.: Il Colosseo, Roma, 1971.

ETIENNE, R.: La vita quotidiana di Pompei, Milán, 1973.

68 Petronio, 40, 5

69 Varrón, I.I., 5,94.

70 Horacio, Art. Poe., 458.

71 Marcial, 14,117. 
FAGAN, G.G.: The lure of the Arena. Social Psychology and the Crowd at the Roman Games, Cambridge, 2011.

GENTILI, B.: Lo spettacolo nel mondo antico. Teatro greco e teatro romano. Roma, 2006.

GIANCOTTI, F.: Mimo e gnomo, Mesina, 1967

GIGLIOLI, C.Q.: «Lampadredomia», en L'Antiquité Classique, 1951, pp. 147-162.

GUILLEN, J.: Urbs Roma. Vida y costumbre de los Romanos. II. Vida publica. Salamanca, 1980.

HARRIS, H.A.: Sport in Grece and Rome, Londres, 1977.

HEURGON, J.: La vie quotidienne chez les Etrusques, París, 1961.

HUMPHREY, J.H.: Roman Circuses, Londres, 1986.

LA REGINA, A.: Sangue e Arena, Roma, 2001.

MANCIOLI, D.: Giochi e Spetacoli, Roma, 1987.

MANODORI, A.: Anfiteatro, circhi e stadi di Roma, Roma, 1982.

MARCATTILI, F.: Circo Maximo. Architetture, funzioni, culti, ideología. Roma, 2009.

NICOLET, C.: Il mestiere di citadino nell'antica Roma, Roma, 1980.

PAOLI, U.E.: Urbs. La vida en la antigua Roma, Barcelona, 1973

PARATORE, E.: Storia del teatro latino, Milán, 1957.

PICCALUGA, G.: Elementi spettacolari nei rituali festivi romani, Roma 1965.

PIGANIOL, A.: Recherches sur les jeux romains, Paris, 1923.

ROBERT, L.: Les Gladiateurs dans l'Orient Grec. Amsterdam, 1971.

SABATINI, P.: Gladiatorium Patia, annunci di spettacoli gladiatori a Pompei, Roma 1980.

SALETTA, V.: Ludi Circensi, Roma, 1964.

SAUNDERS, C.A.: Costume in Roman Comedy, Nueva York, 1909.

THUILLIER, J.P.: «Le progamme «athlétique» des ludi circenses dans la Rome républicaine» en REL 60, 1982, pp. 105-122.

TRAVERSARI,: Gli spettacoli d'aqua nel teatro tardo-antico, Venecia, 1967.

VEYNE, P.: Le pain et le cirque (Sociologie historique d'un pluralismo politique), París, 1976.

VILLE, G.: «les jeux de gladiateurs dans l'Empire chretien», en MEFRA, 72, 1960, pp. 273-335.

VILLE, G.: La gladiature en occident des origenes à la mort de Domitien, BEFAR 245, Roma, 1981.

VISMARA, C.: II suplicio come spettacolo, Roma, 1990.

WEBER, C.W.: Panem et circenses. La politica dei divertimenti di massa nell'antica Roma, Roma, 1986. 
- 19-CABRERO 18/09/2012 10:53 Página 380 